\title{
How clean is "clean"? a review of challenges in apparel consumer laundering technology and cleaning efficiency
}

\begin{abstract}
Comprehensive Life Cycle Assessments of textile and apparel products show that Consumer Use Phase laundering is a major contributor to Global Warming Potential, Ozone Depletion Potential, and Primary Energy Demand. Efforts by laundry machine manufacturers to remedy this situation led to the development of High Efficiency (HE) laundering technology. However, one major challenge is that as laundry machines become more energy-and water-efficient, there is no objective way of knowing whether they are still effective at achieving their fundamental function, i.e., cleaning the garments. This paper presents a review of this challenge and the research needed to address it.
\end{abstract}

Keywords: cleanliness, laundering, textile soils, environmental impact, cleaning performance
Volume 3 Issue 2 - 2017

\author{
Shamini Rajaganesh,' Mourad Krifa ${ }^{2}$ \\ 'Dotand, LLC, USA \\ ${ }^{2}$ Kent State University, USA
}

Correspondence: Mourad Krifa, the Fashion School, Kent State University, USA, Email mkrifa@kent.edu

Received: March 31, 2017 | Published: October 17, 2017

\section{Introduction}

Cleanliness, one of the most essential virtues for humans of all cultures and times, is an abstract concept that is hard to define in both literal and operational terms. In the most practical sense, physical cleanliness is defined as the state of being rid of unwanted, often noxious impurities, and is usually achieved through washing with water and other substances. For a healthy lifestyle, man needs clean food to eat, clean water to drink, a clean environment to live in, and clean clothes to wear. While cleanness of the first three aspects has received ample attention over the years, very little thought has been given to operationalizing the cleanness of clothing and textiles.

Traditionally, garments have been cleaned by means of wet and dry laundry methods which effectiveness has historically been taken for granted. It has generally been assumed that subjecting the soiled textiles for a sufficient duration to a liberal combination of mechanical agitation, thermal energy, water and chemical compounds (e.g., surfactants, solvents, and optical brighteners) is ample to achieve cleanliness. Nevertheless in recent years, there has been a growing concern about the potential environmental impact of those practices.

Indeed, a number of Life Cycle Assessment (LCA) studies focusing on clothing and textiles have consistently underscored the role of laundering as a significant and predominant contributor to the environmental impacts a garment has over its entire life cycle. ${ }^{1-5}$ For instance, a report by the University of Cambridge ${ }^{6}$ estimates that for a typical clothing item such as a T-shirt, approximately $60 \%$ of the carbon associated with the life cycle of the product will be emitted after the clothing is purchased by consumers. A more recent LCA of cotton fiber and fabric found that "Consumer Use Phase laundering was the largest contributor to Global Warming Potential, Ozone Depletion Potential, and Primary Energy Demand". ${ }^{3}$ On the scale of a household, washing clothes and other textiles ranks at or close to the top among the tasks that contribute to the household's energy and water use. $^{7}$

These findings led to a heightened focus on developing new laundry equipment and practices that mitigate the negative environmental impact. ${ }^{2,8-10}$ The recent outcries for energy efficient laundry systems have brought about a change in the laundry habits of people across the world with reductions in the wash temperatures, duration of wash and introduction of new fabric-and environment- friendly detergents. High Efficiency (HE) washers have now become the standard in home laundering and consumers receive significant incentives to switch to HE laundering. While the emphasis on reducing energy and water consumption is very important, the primary purpose of laundering is to satisfy the consumers' need for clean garments. Yet, the assessment of how well this primary purpose of cleaning is achieved has largely been left to claims by machine and detergent manufacturers, and to the consumer's perception..$^{10}$ To date, there is no objective method to measure "cleaning performance" in consumer laundering.

A "good cleaning performance" requires a minimum input of energy, which comprises mechanical agitation, thermal energy, chemicals and time. To maintain a "good cleaning performance", the reduction of one of these four components (for example lowering temperature to reduce energy cost) must be compensated by an increase in one of the others (Pakula \& Stamminger, 2010). However, this balance may be difficult to strike consistently in the absence of an adequate operational definition and of an objective measurement of cleaning performance given the current reliance on subjective assessments. For instance, the US Department of Energy (DOE) has, for over sixty years, led research on energy-efficient and sustainable approaches to laundering. ${ }^{8}$ In this research, water and energy consumption are often measured using quantitative parameters and modeled using advanced computational fluid dynamic algorithms. ${ }^{8}$ On the other hand, the extent to which the laundering process succeeds in achieving its primary purpose, i.e., how well it removes soils from the garments, is often neglected. When it is examined, soil removal or garment cleanness after laundering is usually cited among a host of parameters (including ergonomics, tangling and wear of clothing, noise, vibration...) assessed through surveys and questionnaires (e.g., completed by members of the Association of Home Appliance Manufacturers, AHAM). ${ }^{11}$ 
Contact with the human skin is one of the major sources of laundry soils. ${ }^{12}$ Biologically speaking, the human skin is the largest organ in the human body that performs a variety of functions. Sweating is one of the key tasks performed by the skin to regulate the body core temperature. ${ }^{13}$ Sweating does not always happen due to a thermoregulatory response initiated by the body. Stress and anxiety can cause perspiration (known as emotional sweating), and even spicy food can induce sweating, known as gustatory sweating. ${ }^{13}$

During wear, garments get contaminated with bodily secretions and substances from the surrounding environment, which results in both visible and invisible contaminants. ${ }^{14,15}$ The nature of the soil in clothing differs from person to person, and depends on the occupation and the environment of the wearer. Visible contaminants include stains and solid particulate matter. Invisible contaminants mainly consist of microbes and oily organic substances from the environment, and human body secretions such as sweat, skin shedding and sebum. ${ }^{14}$ Human sebum, a sebaceous secretion of the skin, is a major source of organic soil in clothing. ${ }^{14}$ In particular, squalene, oleic and linoleic acids, as well as triolein have been cited as the components that contribute most to garment soiling. ${ }^{16-18}$ Bowers \& Chantrey ${ }^{16}$ note that these oils are more difficult to remove from polyester than from cotton. These oily contaminations also serve as a nourishing medium on which microorganisms thrive, leading to the development of malodor in clothing. ${ }^{17,19-21}$ Malodor that originates in textiles is secondary in nature as it is a resultant product of bacterial action on sweat and human skin secretions (McQueen et al., 2007). Certain types of bacteria that live on the human skin can produce high-molecular weight, low volatility, and low-water solubility odorous compounds that accumulate on clothing fabric and can become persistent even after several wash/wear cycles. ${ }^{22}$

The major challenge is the lack of adequate measurement of soil removal efficiency. Indeed, while there have been many attempts and strides made toward objectively characterizing the cleanness of food, water and air, there has been very little attention given to the cleanness of clothing. Existing methods, e.g., ASTM D2690-05, rely on subjective evaluation by a panel of assessors of visible stains and odor before and after washing. ${ }^{23}$ Methods relying on instrumental measurement are typically limited to one specific aspect of cleanness, e.g., visible stain removal, ${ }^{24}$ or optical reflectance according to EN 60456. ${ }^{2}$ Such methods do not enable the detection and quantification of the major contaminant found in soiled worn garments, i.e., skin oils and other organic substances transferred to the garment through the contact with the human body. Thus, there is a critical need for an objective test method that enables measuring the amount of soil in a garment and the effectiveness of laundering in removing contaminants such as skin oils and other organic substances.

\section{Acknowledgements}

This short review was adapted from a M.S. thesis by Ms. Shamini Rajaganesh conducted under the supervision of Dr. Mourad Krifa, with support from Cotton Incorporated (14-301).

\section{Conflict of interest}

There are no conflicts of interest.

\section{References}

1. Kalliala EM, Nousiainen P. Life Cycle Assessment-Environmental profile of cotton and polyester-cotton fabrics. Autex Research J. 1999;1(1):8-20.
2. Laitala K, Boks C, Klepp IG. Potential for environmental improvements in laundering. International J Consumer Studies. 2011;35(2):254-264.

3. Life Cycle Assessment of Cotton Fiber \& Fabric. Cotton Incorporated. 2012. p. 156

4. Van der Velden N, Patel M, Vogtländer J. LCA benchmarking study on textiles made of cotton, polyester, nylon, acryl, or elastane. Int J Life Cycle Assess. 2014;19(2):331-356.

5. Beton A, Dias D, Farrant L, et al. Environmental Improvement Potential of Textiles (IMPRO Textiles). In: Wolf O, Cordella M, editors. Joint Research Center Scientific and Technical Reports, European Commission. 2014. p. 194

6. Allwood JM, Laursen SE, Bocken NMP. Well dressed? The present and future sustainability of clothing and textiles in the United Kingdom. University of Cambridge, Institute for Manufacturing, Cambridge, UK; 2006. p. 68.

7. Koerner M, Schulz M, Powell S, et al. The Life Cycle Assessment of Clothes Washing Options for City West Water's Residenttial Customers. 7th Australian Conference on Life Cycle Assessment. Australian Life Cycle Assessment Society, Melbourne, Australia; 2011. p. 44.

8. Richter T. Energy efficient laundry process. GE Global Research Niskayuna, New York, USA; 2005. p. 34.

9. Laitala K, Klepp IG, Boks C. Changing laundry habits in Norway. International J Consumer Studies. 2012;36(2):228-237.

10. Lin J, Iyer M. Cold or hot wash: Technological choices, cultural change, and their impact on clothes-washing energy use in China. Energy Policy. 2007;35(5):3046-3052.

11. Biermayer PJ. Design options for clothes washers. US Department of Energy, Berkeley, California, USA; 1996.

12. Laughlin J, Gold R. Methyl parathion residue removal from protective apparel fabric soiled with synthetic sebum or vegetable oil. Arch Environ Contam Toxicol. 1990;19(2):205-213.

13. Wilke K, Martin A, Terstegen L, et al. A short history of sweat gland biology. Int J Cosmet Sci. 2007;29(3):169-179.

14. Chi YS, Obendorf SK. Aging of oily soils on textile materials: A literature review. J Surfactants \& Detergents. 1998;1(3):407-418.

15. Terpstra MJ. The correlation between sustainable development and home hygiene. American J Infection Control. 2001;29(4):211-217.

16. Bowers CA, Chantrey G. Factors Controlling the Soiling of White Polyester Cotton Fabrics Part I: Laboratory Studies. Textile Res J. 1969;39(1):1-11.

17. Chung H, Seok HJ. Populations of malodor-forming bacteria and identification of volatile components in triolein-soiled cotton fabric. Fibers \& Polymers. 2012;13(6):740-747.

18. Rajaganesh S, Krifa M. Exploring quantitative measures of fabric soil content, in Beltwide Cotton Conferences. National Cotton Council of America, New Orleans, Louisiana, USA; 2014.

19. McQueen RH, Laing RM, Brooks HJL, et al. Odor Intensity in Apparel Fabrics and the Link with Bacterial Populations. Textile Res J. 2007;77(7):449-456

20. McQueen RH, Laing RM, Wilson CA, et al. Odor Retention on Apparel Fabrics: Development of Test Methods for Sensory Detection. Textile Res J. 2007;77(9):645-652.

21. McQueen RH, Keelan M, Xu Y, et al. In vivo assessment of odour retention in an antimicrobial silver chloride-treated polyester textile. J Textile Institute. 2013;104(1):108-117. 
22. Obendorf SK, Kim J, Koniz RF. Measurement of odor development due to bacterial action on antimicrobial polyester fabrics. AATCC Review. 2007;7(7):35-40.

23. ASTM, D2960-05. Standard Test Method of Controlled Laundering Test Using Naturally Soiled Fabrics and Household Appliances. ASTM International. West Conshohocken, Pennsylvania, USA; 2005.
24. Gururajan A, Hequet EF, Sari-Sarraf H. Objective Evaluation of Soil Release in Fabrics. Textile Res J. 2008;78(9):782-795. 